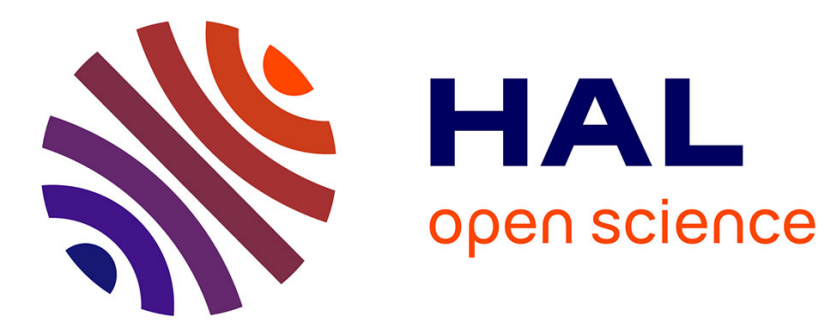

\title{
Cognitive Behavioral Therapy with Daily Mindfulness Training: a Case Report of Comorbid Binge Eating and Bipolar Disorders
}

\author{
Alexis Ruffault, Solène Grégoire, Kelsie Hendrickson, Cécile Flahault
}

\section{- To cite this version:}

Alexis Ruffault, Solène Grégoire, Kelsie Hendrickson, Cécile Flahault. Cognitive Behavioral Therapy with Daily Mindfulness Training: a Case Report of Comorbid Binge Eating and Bipolar Disorders. Mindfulness, 2016, 7 (2), pp.573-576. 10.1007/s12671-015-0446-z . hal-01317546

HAL Id: hal-01317546

https://hal.science/hal-01317546

Submitted on 19 May 2016

HAL is a multi-disciplinary open access archive for the deposit and dissemination of scientific research documents, whether they are published or not. The documents may come from teaching and research institutions in France or abroad, or from public or private research centers.
L'archive ouverte pluridisciplinaire HAL, est destinée au dépôt et à la diffusion de documents scientifiques de niveau recherche, publiés ou non, émanant des établissements d'enseignement et de recherche français ou étrangers, des laboratoires publics ou privés. 


\title{
Cognitive Behavioral Therapy with Daily Mindfulness Training: a Case Report of Comorbid Binge Eating and Bipolar Disorders
}

\author{
Alexis Ruffault ${ }^{1} \cdot$ Solène Grégoire $^{1} \cdot$ Kelsie Hendrickson $^{2} \cdot$ Cécile Flahault $^{1}$
}

\section{(C) Springer Science+Business Media New York 2015}

Brown and Ryan (2003) conceptualized dispositional mindfulness as a self-regulatory function, which is characterized by "being attentive to and aware of what is taking place in the present moment" (p.882). Mindfulness training added to cognitive behavioral therapy (CBT) has been shown to reduce binge eating behavior, drive for thinness, and body dissatisfaction while increasing psychological well-being and quality of life for obese individuals diagnosed with binge eating disorder (BED; Carrard et al. 2011). In order to integrate mindfulness into general psychological practice, clinicians often utilize practical strategies with their clients such as the use of daily reminders, the integration into daily activities, and psychoeducational techniques like educational skill building and stress management (Dimidjian and Kleiber 2013; Shonin et al. 2014). Mindfulness meditation can be trained with between-session practice (Bowen and Kurz 2012). Moreover, mindfulness has been shown to reduce negative mood and impulsivity, as well as increase psychological well-being with clinical and nonclinical populations (Bowen and Kurz 2012; Brown and Ryan 2003).

Highlighting the effects of mindfulness on cognitive and emotional regulation, several studies have shown its benefits for healthier eating patterns and less binge eating (e.g., Baer et al. 2005a, b; Compare et al. 2012; Jordan et al. 2014; Levin et al. 2014). Furthermore, in the treatment of BED, Baer et al.

Alexis Ruffault

alexis.ruffault@gmail.com

1 Laboratoire de Psychopathologie et Processus de Santé (EA 4057), Institut de Psychologie, Université Paris Descartes, 71 Avenue Edouard Vaillant, 92100 Boulogne-Billancourt, France

2 Department of Psychology, Idaho State University, 921 S 8th Avenue, Pocatello, ID 83209, USA (2005a, b) argued that instead of changing thoughts or negative emotional states, the focus should be on making more adapted choices in response to psychological distress via mindfulness rather than binging. In addition to its usefulness with BED populations, mindfulness also targets mental processes that cut across a variety of other psychological disorders (i.e., "transdiagnostic") such as anxiety, depression, substance use, and chronic pain conditions (see Greeson et al. 2014). However, there have been no reports, to our knowledge, that describe a CBT with mindfulness intervention used to treat BED and bipolar disorder in an outpatient clinic setting.

Given that BED and bipolar disorders are highly comorbid (Javaras et al. 2008), we report on the application of a 12-week individual CBT intervention with mindfulness training to the clinical case of an adult patient with bipolar disorder I (BD-I) and BED: a 49-year-old Caucasian woman who contacted AR (first author, health psychologist) as an outpatient to participate in a mindfulness-based therapy because of symptoms related to diagnoses of BD-I, BED, and obesity (BMI= $36 \mathrm{~kg} / \mathrm{m}^{2}$ ). Diagnoses were established by two clinical evaluations: (a) BD-I 20 years ago (after an initial suicide attempt) and (b) BED during the first session of the reported psychotherapy. The patient concurrently had psychiatric support in the community. The patient experienced multiple suicide attempts via intentional ingestion: the first time 20 years ago (when she was initially diagnosed with BD-I) and the last time 3 months prior to beginning the current therapy. Previous psychological supports helped her understand the origins of her psychological distress but did not give her the necessary therapeutic tools to manage it in her everyday life. She was treated with mood stabilizers since her most recent suicide attempt and reported medical adherence. She reported having no prior knowledge of mindfulness and provided written consent to AR to participate in the treatment. 
During therapy sessions, the therapist and patient first discussed the diagnostic criteria for bipolar disorder and $\mathrm{BED}$, and then the therapist provided psychoeducation about mindfulness and how to use it in daily life. Moreover, to increase her mindfulness skills, the patient listened to a mindfulness recording for $10 \mathrm{~min}$ each day as practice. A notebook including (a) a diary for planning mindfulness sessions and writing comments about it, (b) columns to restructure cognitions, and (c) columns to describe the emotional determinants and outcomes of binge episodes was offered to the patient. This tool was provided so that she could engage in selfmanagement care of her disorders. Once per week for 12 weeks, the patient reviewed the notebook with the therapist. During these 1-h face-to-face sessions, the therapist and the patient worked together in an effort to understand the barriers that prevented her from using the notebook throughout the week and to foster the patient's autonomous motivation toward therapy.

At baseline and after every four sessions, the patient completed several self-report questionnaires that measured eating behavior (Three-Factor Eating Questionnaire TFEQ-R18), depression (Beck Depression Inventory, BDI-II; Hospital Anxiety and Depression Scale, HADS-D), anxiety (Hospital Anxiety and Depression Scale, HADS-A), impulsivity (Barratt Impulsiveness Scale, BIS-11), motivation toward therapy (Client Motivation for Therapy Scale, CMOTS), and mindfulness skills (Mindful Attention Awareness Scale, MAAS; Acceptance and Action Question, AAQ-II). The results are displayed in Table 1.

The patient reported less cognitive restriction with food, as well as better controlled and less emotional eating after 12 sessions of weekly psychotherapy. Moreover, she reported a decrease in cognitive impulsivity but maintained high scores in motor impulsivity and nonplanning. Surprisingly, the patient's anxiety scores increased and dispositional mindfulness scores remained stable across the 12-week psychotherapy period. Depression scores were consistent with a major depressive episode experienced within bipolar disorder: the patient showed moderate or severe depression scores every 4 weeks. Motivation scores showed that the patient was more intrinsically motivated toward therapy but more extrinsically motivated when she endorsed severe depression (i.e., after 4 weeks and at post-therapy). Surprisingly, the patient seemed to be as mindful at the end of the therapy as she was at baseline, although her psychological flexibility increased across time in therapy. Furthermore, the patient reported less binge episodes and a more structured meal organization during the second half of psychotherapy.

One of the determinants of BED is the difficulty to cope with psychological distress (Baer et al. 2005a, b), and bipolar disorder can be viewed as a dysfunction in mood regulation (Swann et al. 2007). As BD-I includes manic and depressive episodes, the associations with behavioral impulsivity (including substance abuse) are well known regardless of the type of episode (Swann et al. 2007). This clinical case report aimed to highlight the wide range of applications of daily mindfulness training in obese individuals with BED and other psychiatric comorbidities.

The results reported by the patient are important for clinicians to note for several reasons. First, depression scores assessed with the BDI-II was sensitive to change across therapy while the HADS-D was not. Second, while dispositional mindfulness remained stable, psychological flexibility (i.e., acceptance) increased during the 12-week program. These results suggest that daily mindfulness training and discussions during sessions foster acceptance of thoughts, emotions, and bodily sensations in daily life. Moreover, the patient became more intrinsically and extrinsically motivated toward therapy as the number of sessions progressed. These changes in motivational regulation could be explained by the positive alliance between patient and therapist and by the early stage of change of the patient regarding binge episodes. In fact, the patient never attempted to seek support for her BED prior to the current treatment. Furthermore, the results showed that when depression increased, the patient's motives for attending therapy were more extrinsic (i.e., while feeling depressed, she stated she was attending therapy for the happiness of her therapist instead of her own). This association is similar to literature arguing that motivation is modulated by the satisfaction of psychological needs (Deci and Ryan 1985). Previous research has shown that negative states of mind (e.g., depression) are associated with motivation for change, which may be one explanation for the current observed patterns.

On the other hand, during therapy, the patient reported that she was not always compliant with the daily mindfulness training. She first argued that she did not understand how mindfulness could help her; hence, the therapist educated her on the effects and mechanisms of action of mindfulness. After the psychoeducation sessions, the patient began to put an alarm on her phone to enhance adherence to daily mindfulness training. It seems that understanding the potential benefits of mindfulness training facilitated her involvement and autonomy in her own care. Bowen and Kurz (2012) argued that maintaining long-term mindfulness training and its implementation in everyday life could be obtained by daily practice. In this case, the patient reported that she succeeded at being mindful when difficult situations came in her life, which is in accordance with previous predictions (Bowen and Kurz 2012). A recent study investigating the role played by therapeutic alliance, adherence, and competence in treatment failure showed that both therapeutic alliance and competence are mediators between adherence and treatment success (Weck et al. 2015), suggesting that feeling competent and having a strong alliance with the therapist increases 
Mindfulness

t1.1 Table 1 Scores of the

t1.2 psychological self-reported measures, filled out online every

t1.3 four sessions

t1.4

$\mathrm{t} 1.5$

t1.6

$\mathrm{t} 1.7$

$\mathrm{t} 1.8$

$\mathrm{t} 1.9$

$\mathrm{t} 1.10$

t1.11

$\mathrm{t} 1.12$

$\mathrm{t} 1.13$

$\mathrm{t} 1.14$

t1.15

t1.16

$\mathrm{t} 1.17$

t1.18

t1.19

t1.20

t1.21

t1.22

$\mathrm{t} 1.23$

$\mathrm{t} 1.24$

$\mathrm{t} 1.25$

$\mathrm{t} 1.26$

$\mathrm{t} 1.27$

$\mathrm{t} 1.28$

t1.29

$\mathrm{t} 1.30$

$\mathrm{t} 1.31$

\begin{tabular}{|c|c|c|c|c|c|}
\hline Psychological measures & Possible range & Baseline & 4 weeks & 8 weeks & 12 weeks \\
\hline \multicolumn{6}{|l|}{ Eating behavior (TFEQ-R18) } \\
\hline Cognitive restraint & (0 to 100$)$ & 27.78 & 22.22 & 0.00 & 16.67 \\
\hline Uncontrolled eating & (0 to 100$)$ & 92.59 & 96.30 & 92.59 & 74.07 \\
\hline Emotional eating & (0 to 100$)$ & 100.00 & 100.00 & 88.89 & 88.89 \\
\hline \multicolumn{6}{|l|}{ Depression } \\
\hline BDI-II score & (0 to 63 ) & 22 & 32 & 21 & 36 \\
\hline BDI-II category & & Moderate & Severe & Moderate & Severe \\
\hline HADS-D & $(0$ to 21$)$ & 11 & 15 & 14 & 14 \\
\hline Anxiety (HADS-A) & (0 to 21$)$ & 6 & 13 & 12 & 14 \\
\hline Impulsivity (BIS-11) & & 100.94 & 109.69 & 101.25 & 95.00 \\
\hline Cognitive & & 25.60 & 28.80 & 27.20 & 20.80 \\
\hline Attention & (1 to 4$)$ & 3.15 & 3.95 & 2.40 & 2.80 \\
\hline Cognitive instability & (1 to 4$)$ & 3.00 & 3.00 & 3.00 & 2.00 \\
\hline Motor & & 34.22 & 34.22 & 34.22 & 36.67 \\
\hline Motor & (1 to 4$)$ & 3.71 & 3.43 & 3.43 & 3.14 \\
\hline Perseverance & (1 to 4$)$ & 2.50 & 3.25 & 3.00 & 3.00 \\
\hline Nonplanning & & 37.13 & 41.53 & 36.30 & 35.20 \\
\hline Self-control & (1 to 4$)$ & 3.33 & 3.67 & 3.83 & 3.17 \\
\hline Cognitive complexity & (1 to 4$)$ & 3.40 & 3.60 & 3.20 & 3.20 \\
\hline Motivation toward therapy (CMOTS) & $(-36$ to 36$)$ & 24.92 & 13.00 & 25.83 & 12.33 \\
\hline Amotivation & (1 to 7$)$ & 1.67 & 3.33 & 1.33 & 4.00 \\
\hline External regulation & (1 to 7$)$ & 1.00 & 3.50 & 3.50 & 4.75 \\
\hline Introjected regulation & (1 to 7$)$ & 4.33 & 5.00 & 2.67 & 3.67 \\
\hline Identified regulation & (1 to 7$)$ & 6.00 & 5.75 & 7.00 & 6.75 \\
\hline Integrated regulation & (1 to 7$)$ & 6.50 & 4.50 & 5.75 & 5.25 \\
\hline Intrinsic regulation & (1 to 7$)$ & 5.75 & 6.75 & 7.00 & 6.75 \\
\hline \multicolumn{6}{|l|}{ Mindfulness skills } \\
\hline Dispositional mindfulness (MAAS) & (1 to 6$)$ & 3.47 & 3.13 & 3.13 & 3.07 \\
\hline Psychological flexibility (AAQ-II) & (10 to 70$)$ & 37 & 39 & 35 & 44 \\
\hline
\end{tabular}

AAQ-II Acceptance and Action Questionnaire, BDI-II Beck Depression Inventory, BIS-11 Barratt Impulsiveness Scale, CMOTS Client Motivation for Therapy Scale, HADS Hospital Anxiety and Depression Scale, MAAS Mindful Attention Awareness Scale, TFEQ-R18 Three-Factor Eating Questionnaire adherence to therapy and probability for a successful outcome. In our case, the negative states of mood experienced by the patient could have decreased her feeling of competence, disrupted the relationship between therapeutic alliance, and decreased treatment adherence.

After the 12 planned weeks of therapy, the patient decided to stop seeing AR, stating that the therapy was stressful due to the changes in her "diet" (i.e., from binge episodes to structured eating). The anxiety scores increasing from baseline to post-therapy seem to show the patient's uncertainty during the therapy process. In fact, during weekly sessions, she reported that she did not feel competent. As a clinical health psychologist, it was challenging to address the patient's concurrent mood alterations and concerns about the subjective effectiveness of the therapy. Positive feedback was given when the patient reported improvements in the management of her daily life, but it seems that other techniques should be implemented to minimize anxiety in the behavior change process (i.e., readapting alimentation to replace $\mathrm{BED}$ ).

These findings should be considered in the context of several limitations. First, the therapeutic relationship may have led the patient to give responses she wanted the therapist to see (i.e., response bias), although information given to her about the outcome measures was limited. Second, this is a case of one 49-year-old female patient that should not be taken as representative of the population of patients with BED and BD-I. To our knowledge, this is the first report of a mindfulnessbased intervention for bipolar disorder with multiple suicide attempts and BED. Mindfulness training should be considered as a complementary tool in CBT for improving cognitive regulation of negative emotions across illnesses including obesity, BED, and BD-I. 


\section{Compliance with Ethical Standards}

Conflict of Interest The authors declare that they have no competing interests.

\section{References}

Baer, R. A., Fischer, S., \& Huss, D. B. (2005a). Mindfulness and acceptance in the treatment of disordered eating. Journal of RationalEmotive \& Cognitive-Behavior Therapy, 23(4), 281-300. doi:10. 1007/s10942-005-0015-9.

Baer, R. A., Fischer, S., \& Huss, D. B. (2005b). Mindfulness-based cognitive therapy applied to binge eating: a case study. Cognitive and Behavioral Practice, 12(3), 351-358. doi:10.1016/S1077-7229(05) 80057-4.

Bowen, S., \& Kurz, A. S. (2012). Between-session practice and therapeutic alliance as predictors of mindfulness after mindfulnessbased relapse prevention: predictors of mindfulness. Journal of Clinical Psychology, 68(3), 236-245. doi:10.1002/jclp. 20855.

Brown, K. W., \& Ryan, R. M. (2003). The benefits of being present: mindfulness and its role in psychological well-being. Journal of Personality and Social Psychology, 84(4), 822-848. doi:10.1037/ 0022-3514.84.4.822.

Carrard, I., Crépin, C., Rouget, P., Lam, T., Golay, A., \& Van der Linden, M. (2011). Randomised controlled trial of a guided self-help treatment on the Internet for binge eating disorder. Behaviour Research and Therapy, 49, 482-491. doi:10.1016/j.brat.2011.05.004.

Compare, A., Callus, E., \& Grossi, E. (2012). Mindfulness trait, eating behaviours and body uneasiness: a case-control study of binge eating disorder. Eating and Weight Disorders, 17(4), e244-e251. doi: $10.3275 / 8652$.
Deci, E. L., \& Ryan, R. M. (1985). Intrinsic motivation and selfdetermination in human behavior. New York: Plenum.

Dimidjian, S., \& Kleiber, B. (2013). Being mindful about the use of mindfulness in clinical contexts. Cognitive and Behavioral Practice, 20(1), 57-59. doi:10.1016/j.cbpra.2012.02.006.

Greeson, J., Garland, E. L., \& Black, D. (2014). Mindfulness: a transtherapeutic approach for transdiagnostic mental processes. In A. Ie, C. T. Ngnoumen, \& E. J. Langer (Eds.), The Wiley-Blackwell handbook of mindfulness (1st ed., pp. 533-562). Oxford: John Wiley \& Sons, Ltd.

Javaras, K. N., Pope, H. G., Lalonde, J. K., Roberts, J. L., Nillni, Y. I., Laird, N. M., ... Hudson, J. I. (2008). Co-occurrence of binge eating disorder with psychiatric and medical disorders. The Journal of Clinical Psychiatry, 69(2), 266-273.

Jordan, C. H., Wang, W., Donatoni, L., \& Meier, B. P. (2014). Mindful eating: trait and state mindfulness predict healthier eating behavior. Personality and Individual Differences, 68, 107-111. doi:10.1016/j. paid.2014.04.013.

Levin, M. E., Dalrymple, K., Himes, S., \& Zimmerman, M. (2014). Which facets of mindfulness are related to problematic eating among patients seeking bariatric surgery? Eating Behaviors, 15(2), 298-305. doi:10.1016/j.eatbeh.2014.03.012.

Shonin, E., Van Gordon, W., \& Griffiths, M. D. (2014). Practical tips for using mindfulness in general practice. British Journal of General Practice, 64(624), 368-369. doi:10.3399/bjgp14X680725.

Swann, A. C., Gerard Moeller, F., Steinberg, J. L., Schneider, L., Barratt, E. S., \& Dougherty, D. M. (2007). Manic symptoms and impulsivity during bipolar depressive episodes. Bipolar Disorders, 9(3), 206-212.

Weck, F., Grikscheit, F., Jakob, M., Höfling, V., \& Stangier, U. (2015). Treatment failure in cognitive-behavioural therapy: therapeutic alliance as a precondition for an adherent and competent implementation of techniques. British Journal of Clinical Psychology, 54(1), 91-108. doi:10.1111/bjc.12063. 